\title{
Mismatch of corneal specialists' expectations and keratoconus knowledge in general ophthalmologists - a prospective observational study in Switzerland
}

Philipp B. Baenninger ${ }^{1,2^{*}}$, Lucas M. Bachmann ${ }^{1,3}$, Katja C. Iselin², Oliver A. Pfaeffli², Claude Kaufmann ${ }^{1,2}$, Michael A. Thiel ${ }^{1,2}$ and Gerd Gigerenzer ${ }^{4}$

\begin{abstract}
Background: To assess whether Swiss general ophthalmologists have the minimal keratoconus knowledge that corneal specialists would expect them to have.

Methods: Corneal specialists defined "minimal keratoconus knowledge" (MKK) with respect to definition, risk factors, symptoms and possible treatment options of keratoconus. A telephone interview survey was conducted among one hundred ophthalmologists (mean age 51.9 years (SD 9.5), $60 \%$ male) from the German-speaking part of Switzerland. For each participant, years of work experience, number of keratoconus patients seen per year and access to a topography device were obtained. We calculated the proportion of MKK and examined in multivariate analyses whether ophthalmologists with access to topography and with greater work experience performed better than other groups.

Results: No single ophthalmologist had MKK. The mean MKK was $52.0 \%$, and the range was 28.6-81.0\%. Per 10 years of working in private practice, the MKK decreased by $8.1 \%$ points ( $95 \% \mathrm{Cl}:-14.2,-2.00 ; p=0.01$ ). Only $24 \%$ of participants correctly recalled the definition of keratoconus, $9 \%$ all risk factors, $5 \%$ all symptoms and $20 \%$ all treatment modalities. The MKK values were not associated with the number of keratoconus patients seen per year and the availability of topography to diagnose keratoconus.

Conclusions: There is a substantial mismatch between corneal specialist' expectations and general ophthalmologists' knowledge about keratoconus. The low recall of symptoms and risk factors may explain why ophthalmologists diagnose relatively few cases of keratoconus, resulting in inefficient care delivery and delayed intervention.
\end{abstract}

Keywords: Medical education, minimal knowledge, keratoconus, general ophthalmologist, mismatch, interview survey

\footnotetext{
* Correspondence: philipp.baenninger@luks.ch

${ }^{1}$ Faculty of Medicine, University of Zurich, 8091 Zurich, Switzerland

2Department of Ophthalmology, Cantonal Hospital of Lucerne, 6000 Lucerne-16, Switzerland

Full list of author information is available at the end of the article
}

C C The Author(s). 2021 Open Access This article is licensed under a Creative Commons Attribution 4.0 International License, which permits use, sharing, adaptation, distribution and reproduction in any medium or format, as long as you give appropriate credit to the original author(s) and the source, provide a link to the Creative Commons licence, and indicate if changes were made. The images or other third party material in this article are included in the article's Creative Commons licence, unless indicated otherwise in a credit line to the material. If material is not included in the article's Creative Commons licence and your intended use is not permitted by statutory regulation or exceeds the permitted use, you will need to obtain permission directly from the copyright holder. To view a copy of this licence, visit http://creativecommons.org/licenses/by/4.0/. The Creative Commons Public Domain Dedication waiver (http://creativecommons.org/publicdomain/zero/1.0/) applies to the data made available in this article, unless otherwise stated in a credit line to the data. 


\section{Background}

Keratoconus is a progressive corneal disease in which the cornea, normally round, thins and begins to bulge out in a cone shape. This cone shape deflects light as it enters the eye on its way to the light-sensitive retina, causing distorted vision. Treatment focuses on stopping progression with collagen crosslinking and on visual rehabilitation with glasses, rigid contact lenses or corneal transplants [1]. Keratoconus can be diagnosed clinically by slit-lamp findings. However, clinical manifestations are mainly seen in moderate to severe stages of the disease. Conversely, in the earliest stages of keratoconus, there may be no obvious changes, resulting in the majority of these patients going undiagnosed [2]. In the last two decades, however, there has been a major advancement in knowledge of how to diagnose the disease. Based on Scheimpflug imaging, corneal topography systems produce a 3-D image of the anterior eye segment and provide details of the anterior and posterior corneal surfaces as well as pachymetry [3], allowing ophthalmologists to detect keratoconus at a much earlier stage than was previously possible [4]. The prevalence of keratoconus is generally reported as 1:375 [5] to 1:2000 [6] but varies worldwide: from 0.3 to 100,000 in Russia [7] to 54.5 per 100,000 in the United States [6] to 86 per 100, 000 in Denmark[8]. Variability may be due to differences in study methodology and design, environmental or genetic factors, or diagnostic criteria and instruments [9]. In addition, current literature reports a much higher prevalence of up to 1:20 [10], which raises the question of whether there is a high rate of undiagnosed keratoconus patients who do not have access to the necessary care. There are no published data on the prevalence of keratoconus in Switzerland nor on the rate of undiagnosed patients, due to the lack of a national screening programme or a national keratoconus registry. In the Swiss healthcare system, patients can seek advice on vision problems from opticians, general practitioners or general ophthalmologists. Therefore, no general standardised referral practice is in place, and keratoconus patients are typically under the care of their primary board-certified general ophthalmologist and see a corneal specialist at a tertiary referral hospital for topographic diagnosis, assessment of keratoconus progression and advice on treatment options.

Modern keratoconus management requires that patients and their ophthalmologists engage in a shared decision-making process. Shared decision making helps to improve the match between treatment options and patients' personal values and preferences [11]. However, active participation requires patients to have at least a minimal level of understanding of the disease [12]. In a previous study, corneal specialists defined "minimal keratoconus knowledge" (MKK) regarding definition, risk factors, symptoms and possible treatment options of keratoconus and found a dramatic lack of knowledge in keratoconus patients [13]. Given the evidence for a high rate of undiagnosed keratoconus patients in the general population, we wanted to know if lack of knowledge and awareness of keratoconus in general ophthalmologists in Switzerland could be a contributing factor. By conducting the same survey on MKK with a group of general ophthalmologists, we aimed to find out specifically whether there is a potential mismatch between specialists' expectations and general ophthalmologists' knowledge about keratoconus.

\section{Materials and methods \\ Study Design}

We conducted a single-center, prospective telephone interview survey at a tertiary referral center in Lucerne, Switzerland with general ophthalmologists in private practice in the German-speaking part of Switzerland.

Inclusion criteria were board-certified ophthalmologists working in a general ophthalmology practice in the German-speaking part of Switzerland who had sufficient German-language skills. The exclusion criterion was inability to follow the German questionnaire due to language comprehension problems. This was not assessed systematically, but interviewers were allowed to exclude such participants at their own judgement.

We informed eligible ophthalmologists by postal letter about the survey on keratoconus and contacted them 1 week later by telephone to assess their interest in participating. If they verbally consented, we agreed on a specific date to conduct a telephone interview based on the open-ended questionnaire with no time restrictions. We did not record the interview. We enrolled ophthalmologists willing to participate in the study in a prospective and consecutive manner. They were offered no incentives for participation.

\section{Questionnaire development}

In a previous study [13] assessing MKK in patients, a questionnaire was developed on the basis of a literature review and discussions held by a focus group of four corneal specialists and two contact lens-fitting optometrists. They defined the minimal knowledge an average keratoconus patient should have in relation to definition, risks and triggers, symptoms and treatment options of the disease. They were instructed to restrict these to the most common set of characteristics that should be known by every keratoconus patient, excluding uncommon factors or unusual presentations of symptoms. In telephone interviews among ophthalmologists, we employed the same questionnaire than the one used to assess MKK in patients [13]. Although ophthalmologists arguably know more about the condition than patients, 
we refrained from expanding the questionnaire in order to ensure uniform assessment of patients and physicians. Table 1 defines what we considered minimal knowledge.

Besides developing the knowledge questions and obtaining demographic participant information, we planned to extract data on years of work experience, number of keratoconus patients seen per year and access to a topography device. We tested the questionnaire on five subjects to obtain its final form. The relevant ethic committee of Lucerne reviewed the protocol of this study (ReqID-2019-00995) and found that this study did not fall under the Swiss Human Research Act.

\section{Questionnaire items}

The first question assessed participants' knowledge on the definition of keratoconus, with three possible answers: thinning of the cornea, irregular astigmatism and protrusion of the cornea. In the second question, risk factors for the occurrence of keratoconus, such as positive family

Table 1 Survey interview questionnaire

\begin{tabular}{|c|c|}
\hline Question 1 & What is keratoconus? \\
\hline Correct answers: & $\begin{array}{l}\text { - Thinning of the cornea (56\%) } \\
\text { - Irregular astigmatism (68\%) } \\
\text { - Protrusion of the cornea (64\%) }\end{array}$ \\
\hline Question 2 & $\begin{array}{l}\text { Are there risk factors for the occurrence of } \\
\text { keratoconus? }\end{array}$ \\
\hline Correct answers: & $\begin{array}{l}\text { - Positive family history (79\%) } \\
\text { - Allergies (48\%) } \\
\text { - Younger age (29\%) }\end{array}$ \\
\hline Question 3 & What are triggers for the onset of keratoconus? \\
\hline Correct answers: & $\begin{array}{l}\text { - Eye rubbing }(69 \%) \\
\text { - Puberty }(16 \%) \\
\text { - Pregnancy }(4 \%)\end{array}$ \\
\hline Question 4 & What are symptoms of keratoconus? \\
\hline Correct answers: & $\begin{array}{l}\text { - Deterioration of vision (short-sightedness, } \\
\text { astigmatism) ( } 97 \%) \\
\text { - Double vision (shadow vision) (31\%) } \\
\text { - Light sensitivity (13\%) }\end{array}$ \\
\hline Question 5 & $\begin{array}{l}\text { What are consequences of untreated } \\
\text { keratoconus? }\end{array}$ \\
\hline Correct answer: & $\begin{array}{l}\text { - Visual deterioration (86\%) } \\
\text { - Inability to wear glasses (65\%) } \\
\text { - Inability to wear contact lenses (38\%) } \\
\text { - Restriction of current occupation (8\%) } \\
\text { - Need for a corneal transplant (36\%) }\end{array}$ \\
\hline Question 6 & What are treatment options for keratoconus? \\
\hline Correct answers: & $\begin{array}{l}\text { - Glasses (33\%) } \\
\text { - Rigid contact lenses (81\%) } \\
\text { - Corneal cross-linking (100\%) } \\
\text { - Corneal transplant (72\%) }\end{array}$ \\
\hline
\end{tabular}

The MKK is computed in the following way. There are six questions for which the minimal correct answers vary between three and five. The total number of correct answers is 21 . The MKK of a person is the total number of correct replies times 100 divided by 21 . Please note that MKK measures only the minimal knowledge. Additional knowledge that may be important is not measured. Percentage (\%) of correct participants' $(n=100)$ answers are displayed in parenthesis history, allergies and younger age were asked for. The third question concerned triggers for the onset of keratoconus, with possible answers comprising eye rubbing, puberty and pregnancy. In the fourth question, participants were requested to name symptoms of keratoconus; possible answers were deterioration of vision, double vision and light sensitivity. The fifth question asked about the consequences of untreated keratoconus, which are visual deterioration, inability to wear glasses, inability to wear contact lenses, restriction of current occupation and need for corneal transplantation. The final question asked for treatment options for keratoconus, such as glasses, rigid contact lenses, corneal cross-linking and corneal transplantation.

\section{Interviewers}

Two interviewers received an oral and written instruction on how to conduct the interview, and were trained with four test interviewees. Both interviewers were German native speakers and had a professional background as specialized study nurses working in an ophthalmology department. All four test interviewees were board-certified, German-speaking ophthalmologists working in the same ophthalmology department but not members of the corneal unit. The interviewers were specifically instructed not to prompt the interviewees on how many answers to give per question.

\section{Statistical analysis}

Two corneal specialists independently assessed and classified the replies using an assessment sheet with prespecified correct replies. Statements made during the interview that pointed at a correct reply without perfectly fitting the pre-specified replies were recorded and discussed between the two assessors. Disagreements were resolved by consensus.

The total number of correct answers was 21. The MKK of a person equaled the total number of correct replies multiplied by one hundred divided by 21 . In addition, we examined the influence of age (interval scaled), gender (female; male), years of work experience, number of keratoconus patients seen per year and access to a topography device as independent variables and the cumulative proportion of correct replies as the dependent variable using a linear multivariable regression model. We performed the analysis using the Stata 16.1 statistical software package (StataCorp, 4905 Lakeway Drive, College Station, Texas 77,845 USA).

\section{Results}

\section{Reporting of participant characteristics}

In January 2020 we informed 191 ophthalmologists by postal letter about the survey and contacted them 1 week later by telephone. 117 ophthalmologists initially agreed to participate and 100 ophthalmologists (mean 
age 51.9 years (SD 9.5), $60 \%$ male) were ultimately available for the interview. None of them had to be excluded due to poor German-speaking skills. Two corneal specialists independently assessed and classified the replies: in two cases, consensus was not reached $(0.05 \%)$ and the reply was rated as "correct" (i.e., in favor of the ophthalmologist).

The 100 ophthalmologists included in the survey correspond to $17.6 \%$ of ophthalmologists practicing in private practice in the German-speaking part of Switzerland. On average, participants had 16.1 years (SD 9.67) of working experience. The estimated median number of keratoconus patients seen per year was eight (IQR 4.5 to 20), and $60 \%$ of respondents reported having access to a state-of-the-art topography device to detect keratoconus. Fourteen participants (14\%) had experience in surgical interventions such as corneal crosslinking or corneal graft surgery. Demographics of participants are summarized in Table 2.

\section{MKK - performance}

The mean MKK was $52.0 \%$, and the range was 28.6$81.0 \%$. The multivariable analysis assessing the association between participants' characteristics and MKK found no significant parameter (Table 3). Percentage of correct answers are outlined in Table 1.

\section{MKK - definitions, risk factors and triggers}

Whereas 42 (42\%) of the ophthalmologists recalled that irregular astigmatism and protrusion are two diagnostic indicators for keratoconus, only 24 participants (24\%) recalled all three relevant parameters (including corneal thinning). Of the three most important risk factors for the development of keratoconus, 79 subjects $(79 \%)$ correctly stated "positive family history", while allergies (48\%) and younger age (29\%) were less often recalled. Only $9 \%$ of participants correctly recalled all risk factors. Regarding triggers, eye rubbing was named most often $(69 \%)$; puberty (16\%) and pregnancy (4\%) were rarely mentioned.

MKK - symptoms, consequences of untreated keratoconus The majority of participants stated that deterioration of vision was an important symptom of keratoconus (97\%), while other important symptoms, including double

Table 2 Participant demographics

\begin{tabular}{lll}
\hline Participants $(\mathbf{n}=\mathbf{1 0 0})$ & & \%/SD/IQR \\
\hline Mean age (years) & 51.9 & SD 9.5 \\
Male gender & 60 & $60 \%$ \\
Mean working experience (years) & 16.1 & SD 9.67 \\
Median number of keratoconus patients per year & 8 & IQR 4.5 to 20 \\
Access to topography device & 60 & $50 \%$ \\
Experience in surgical interventions & 14 & $14 \%$ \\
\hline
\end{tabular}

vision (31\%) and light sensitivity (13\%) were less frequently specified. Regarding consequences of untreated keratoconus, progression of visual deterioration (86\%) was most commonly named. Other consequences, including the requirement of a corneal transplant (36\%), the inability to fit glasses $(65 \%)$ or even contact lenses (38\%) were mentioned less often.

Eight respondents acknowledged that keratoconus progression could impede patients from continuing working in their current profession. Five participants correctly answered all questions concerning symptoms, and three participants correctly answered all questions concerning consequences of untreated keratoconus.

\section{MKK- treatment options}

All participants stated that corneal cross-linking was one of the treatment modalities, followed by rigid contact lenses $(81 \%)$ and corneal transplant $(72 \%)$. Glasses, as the fourth option, was seldom reported (33\%). Twenty participants (20\%) answered all questions regarding treatment options correctly.

\section{Discussion \\ Main findings}

In this interview survey we found a substantial mismatch between corneal specialists' expectations and general ophthalmologists' knowledge about the typical signs, risk factors and treatment options for keratoconus. Overall, participants recalled only approximately half of the MKK. Contrary to our expectation, a higher number of keratoconus patients seen per year or access to topography devices did not increase MKK.

\section{Results in light of existing literature}

Up to now, little was known about differences in general ophthalmologists' and corneal specialists' knowledge regarding chronic eye disease such as keratoconus. AbuAmara et al. reported a substantial mismatch of expected primary care physicians' knowledge for the screening and treatment of sight-threatening diabetic retinopathy $[14,15]$. In another study, only $52 \%$ of primary care physicians indicated having adequate knowledge to advise their patients on vision health [16]. There is substantial evidence in the medical literature for such differences between generalists and specialists in terms of knowledge, patterns of care and clinical outcomes for a broad range of diseases [17]. Specialists were shown to be more knowledgeable about the management of selected general medicine conditions $[15,18]$. Several reasons account for their higher level of knowledge: specialists benefit from treating a narrower range of clinical problems [15], can devote more time to continuing education relevant to such conditions [19] and may have better access to the most recent information 
Table 3 Multivariate analysis assessing the association between participants' characteristics and MKK

\begin{tabular}{lllll}
\hline MKK & Coefficent & Standard Error & $\boldsymbol{p}$-value & 95 \% Confidence Interval \\
\hline Age & -5.82 & 3.83 & 0.13 & -13.4 to 1.8 \\
Sex (female) & -1.06 & 2.83 & 0.71 & -6.7 to 4.6 \\
Access to topography & -3.25 & 2.92 & 0.27 & -9.1 to 2.6 \\
Average keratoconus patients seen per year & 0.08 & 0.06 & 0.16 & -0.1 to 0.2 \\
Years in private practice & 0.34 & 0.35 & 0.33 & -0.3 to 1.0 \\
\hline
\end{tabular}

than generalists [20]. Given that most ophthalmologists in this cohort see on average one keratoconus patient out of an estimated 700 patients per month in their daily routine, the condition is probably diagnosed too rarely to justify keeping up with the latest developments in the field. Interestingly, some of the replies given by the ophthalmologists were not considered to be MKK, yet were nevertheless correct. Among them, presence of Down Syndrome (31\%) and connective tissue disorders (9\%) were commonly stated risk factors. However, in the group of ophthalmologists naming Down Syndrome as a risk factor, none of the participants named all other risk factors correctly.

\section{Strengths and limitations}

To the best of our knowledge, this is the first survey investigating knowledge about keratoconus in general ophthalmologists.

What are the limitations of this study? We assessed a convenience sample of limited size representing $10 \%$ of all ophthalmologists working in hospitals and private practices in Switzerland. We enrolled only ophthalmologists in private practice willing to participate in the study, which might have introduced selection bias, although we believe that our respondents were in fact more likely to score higher than average, leading to an overestimation of knowledge. We cannot rule out that some particularities in the Swiss continuous education system may impede broad generalizations of our findings to other countries. A further limitation was that we used a non-validated questionnaire. Because no standard and validated questionnaire was available, we designed one according to published recommendations [21]. The questionnaire only fulfilled the element of face validity, which is an important but not sufficient element of questionnaire development. However, the questionnaire was sufficient to point out the substantial mismatch of expected and actual knowledge. Finally, this was a recall test, which is usually more challenging than a recognition test such as multiple-choice exams. Arguably, conducting the interview on the phone created another potential stressor for participants. On the other hand, in our opinion a recall test is more likely to represent the doctors' behavior in their daily practice than a recognition test. Shared decision making requires knowledge about the disease, justifying our approach [22].
Furthermore, independent research has clearly shown that medical knowledge assessed by a recognition test was also limited in medical students and senior medical educators [23].

\section{Implications for research and practice}

Further research should aim at defining ideal pathways for patient care between general ophthalmologists and corneal specialists in the management of keratoconus. The potential lack of keratoconus knowledge probably reduces awareness of the disease, which impedes patients from being diagnosed at an early stage of the disease and leads to a potentially worse outcome in the long-term. On the other hand, there are still debates among keratoconus specialists about the use of updated classification or surgical management [1]. Therefore, if specialists do not reach a consensus on various aspects of the condition, it is difficult to expect general ophthalmologists to improve their keratoconus management. Nevertheless, there is a need of better general ophthalmologist training on keratoconus to achieve a broader awareness of this condition. Substantial improvement is also needed in interdisciplinary patient care, such as between contact lens specialists, general ophthalmologists and corneal specialists. So far, no established collaborations, networks or common advanced training platforms exist in Switzerland.

\section{Conclusions}

We found a substantial mismatch between corneal specialists' expectations and general ophthalmologists' knowledge about keratoconus. Our particular sample had half of the MKK that corneal specialists would expect patients to know, independent of the number of keratoconus patients seen and of access to a state-of-the art topography device. Almost one half of ophthalmologists recalled only one diagnostic criterion of keratoconus, which may be a reason for the low reported keratoconus prevalence in Switzerland compared with in other countries. Under-detection of early keratoconus may lead to delayed intervention and a substantial disease burden of those patients.

Abbreviation

MKK: Minimal keratoconus knowledge. 


\section{Acknowledgements}

Not applicable.

\section{Authors' contributions}

PBB Conception of work, data acquisition, writing of manuscript. LMB Data analysis and interpretation, writing of manuscript. KCI Data Acquisition. OP Data Acquisition. CK Substantial revision. MAT Substantial revision. GG Conception of work, substantial revision. The author(s) read and approved the final manuscript.

\section{Funding}

Not applicable.

\section{Availability of data and materials}

The datasets used and/or analyzed during the current study are available from the corresponding author on reasonable request.

\section{Declarations}

\section{Ethics approval and consent to participate}

The relevant ethic committee of Lucerne reviewed the protocol of this study (ReqID-2019-00995) and found that this study did not fall under the Swiss Human Research Act. All participants provided informed consent to participate in the study. All methods were carried out in accordance with relevant guidelines and regulations.

\section{Consent for publication}

Not applicable.

\section{Compeitng interests}

The authors declare that they have no competing interests.

\section{Author details}

'Faculty of Medicine, University of Zurich, 8091 Zurich, Switzerland. 2 Department of Ophthalmology, Cantonal Hospital of Lucerne, 6000 Lucerne-16, Switzerland. ${ }^{3}$ Medignition Inc. Research Consultants Zurich, Verena Conzett-Strasse 9, PO 9628, 8036 Zurich, Switzerland. ${ }^{4}$ Max Planck Institute for Human Development, Lentzeallee 94, 14195 Berlin, Germany.

Received: 4 January 2021 Accepted: 5 May 2021

Published online: 25 May 2021

\section{References}

1. Gomes JA, Tan D, Rapuano CJ, Belin MW, Ambrósio R, Jr., Guell JL, Malecaze F, Nishida K, Sangwan VS: Global consensus on keratoconus and ectatic diseases. Cornea 2015;34:359-369.

2. Olivo-Payne A, Abdala-Figuerola A, Hernandez-Bogantes E, Pedro-Aguilar L, Chan E, Godefrooij D: Optimal management of pediatric keratoconus: Challenges and solutions. Clin Ophthalmol 2019;13:1183-1191.

3. Motlagh MN, Moshirfar M, Murri MS, Skanchy DF, Momeni-Moghaddam H, Ronquillo YC, Hoopes PC: Pentacam ${ }^{\circledR}$ corneal tomography for screening of refractive surgery candidates: A review of the literature, part i. Med Hypothesis Discov Innov Ophthalmol 2019;8:177-203.

4. Belin MW, Villavicencio OF, Ambrosio RR: Tomographic parameters for the detection of keratoconus: Suggestions for screening and treatment parameters. Eye Contact Lens 2014;40:326-330.

5. Godefrooij DA, de Wit GA, Uiterwaal CS, Imhof SM, Wisse RP: Age-specific incidence and prevalence of keratoconus: A nationwide registration study. Am J Ophthalmol 2017;175:169-172.

6. Kennedy RH, Bourne WM, Dyer JA: A 48-year clinical and epidemiologic study of keratoconus. Am J Ophthalmol 1986;101:267-273.

7. Gorskova EN, Sevostianov EN: [epidemiology of keratoconus in the urals]. Vestn Oftalmol 1998:114:38-40

8. Nielsen $\mathrm{K}$, Hjortdal J, Aagaard Nohr E, Ehlers N: Incidence and prevalence of keratoconus in denmark. Acta Ophthalmol Scand 2007:85:890-892.

9. Gokhale NS: Epidemiology of keratoconus. Indian J Ophthalmol 2013;61: 382-383.

10. Netto EAT, Al-Otaibi WM, Hafezi NL, Kling S, Al-Farhan HM, Randleman JB, Hafezi F: Prevalence of keratoconus in paediatric patients in riyadh, saud arabia. Brit J Ophthalmol 2018;102:1436-1441.
11. Stegmann ME, Festen S, Brandenbarg D, Schuling J, van Leeuwen B, de Graeff P, Berendsen AJ: Using the outcome prioritization tool (opt) to assess the preferences of older patients in clinical decision-making: A review. Maturitas 2019:128:49-52.

12. Brunner F, Gymesi A, Kissling R, Bachmann LM: Disease-related knowledge of patients with chronic regional pain syndrome. Journal of rehabilitation medicine 2010;42:458-462.

13. Baenninger PB, Bachmann LM, Ritzmann M, Blaser F, Gatzioufas Z, Alder M, Handzic A, Iselin K, Kaufmann C, Thiel MA. Do patients with keratoconus have minimal disease knowledge? Cornea. 2021;40(5):624-7. https://doi. org/10.1097/ICO.0000000000002501.

14. Abu-Amara TB, Al Rashed WA, Khandekar R, Qabha HM, Alosaimi FM, Alshuwayrikh AA, Almadi MK, Alfaris A: Knowledge, attitude and practice among non-ophthalmic health care providers regarding eye management of diabetics in private sector of riyadh, saudi arabia. BMC Health Serv Res 2019;19:375.

15. Ayanian JZ, Hauptman PJ, Guadagnoli E, Antman EM, Pashos CL, McNeil BJ: Knowledge and practices of generalist and specialist physicians regarding drug therapy for acute myocardial infarction. N Engl J Med 1994;331:11361142

16. Ammary-Risch N, Kwon HT, Scarbrough W, Higginbotham E, Heath-Watson S: Minority primary care physicians' knowledge, attitudes, and practices on eye health and preferred sources of information. J Natl Med Assoc 2009;101: 1247-1253

17. Harrold LR, Field TS, Gurwitz JH: Knowledge, patterns of care, and outcomes of care for generalists and specialists. J Gen Intern Med 1999;14:499-511.

18. Friedmann PD, Brett AS, Mayo-Smith MF: Differences in generalists' and cardiologists' perceptions of cardiovascular risk and the outcomes of preventive therapy in cardiovascular disease. Ann Intern Med 1996;124:414-421.

19. Jollis JG, DeLong ER, Peterson ED, Muhlbaier LH, Fortin DF, Califf RM, Mark DB: Outcome of acute myocardial infarction according to the specialty of the admitting physician. N Engl J Med 1996;335:1880-1887.

20. Markson LE, Cosler LE, Turner BJ: Implications of generalists' slow adoption of zidovudine in clinical practice. Arch Intern Med 1994;154:1497-1504.

21. Boynton PM, Greenhalgh T: Selecting, designing, and developing your questionnaire. BMJ (Clinical research ed) 2004;328:1312-1315

22. Bae JM: Shared decision making: Relevant concepts and facilitating strategies. Epidemiol Health 2017;39:e2017048.

23. Jenny MA, Keller N, Gigerenzer G: Assessing minimal medical statistical literacy using the quick risk test: A prospective observational study in germany. BMJ Open 2018;8:e020847.

\section{Publisher's Note}

Springer Nature remains neutral with regard to jurisdictional claims in published maps and institutional affiliations.

Ready to submit your research? Choose BMC and benefit from:

- fast, convenient online submission

- thorough peer review by experienced researchers in your field

- rapid publication on acceptance

- support for research data, including large and complex data types

- gold Open Access which fosters wider collaboration and increased citations

- maximum visibility for your research: over $100 \mathrm{M}$ website views per year

At BMC, research is always in progress.

Learn more biomedcentral.com/submission 